Int. J. Plant Sci. 171(5):509-518. 2010.

(c) 2010 by The University of Chicago. All rights reserved.

1058-5893/2010/17105-0005\$15.00 DOI: $10.1086 / 651944$

\title{
MATERNAL EFFECTS OF HERBIVORY IN IMPATIENS CAPENSIS
}

\author{
Janette A. Steets ${ }^{1, *}$ and Tia-Lynn Ashmant
}

*Department of Botany, Oklahoma State University, Stillwater, Oklahoma 74078, U.S.A.; and tDepartment of Biological Sciences, University of Pittsburgh, Pittsburgh, Pennsylvania 15260, U.S.A., and Pymatuning Laboratory of Ecology, Linesville, Pennsylvania 16424, U.S.A.

Maternal effects of herbivory for fitness-related traits of offspring, especially those traits that are expressed later in a plant's life, have rarely been studied. To better understand how herbivory to the maternal plant influences traits of its progeny and whether this depends on the mating system that produced the seed or the growth environment of the seedling, we examined maternal effects of herbivory in Impatiens capensis. Impatiens capensis is well suited to this study because it exhibits a mixed mating system by producing obligately selfing cleistogamous flowers and facultatively outcrossing chasmogamous flowers on a single plant. In a natural $I$. capensis population, we manipulated maternal herbivory and collected seeds from cleistogamous and chasmogamous flowers and assessed their fitness in the presence or absence of intraspecific competitors in the greenhouse. We found that maternal herbivory had positive effects for many offspring traits but the magnitude of the maternal effect depended on the offspring competitive context. In addition, for offspring biomass and total flower production, the expression of maternal effects varied with seed source (i.e., chasmogamous or cleistogamous flower). Our results demonstrate that maternal herbivory has consequences for the next generation that persist throughout the offspring life cycle, indicating that there may be important demographic consequences of maternal effects.

Keywords: intraspecific competition, outcrossing, selfing, transgenerational effects, vegetative herbivory.

\section{Introduction}

Many studies have examined the contribution of the maternal abiotic environment (e.g., moisture, temperature, nutrients, light) to offspring phenotype and fitness (e.g., Lacey 1996; Sultan 1996; Huxman et al. 1998; Galloway 2001a, 2001b; Lundgren and Sultan 2005; Galloway and Etterson 2007). Less well studied are the consequences of the maternal biotic environment, such as herbivory and competition, to offspring trait expression. Herbivory is not only a ubiquitous biotic factor affecting plant populations, but it may also lead to significant maternal environmental effects because it reduces photosynthetic capacity and, thus, plant resources (Crawley 1983). Herbivory-mediated reduction in resource availability may have consequences for plant fitness via effects on both the number of progeny produced and the quality of those progeny (e.g., Marquis 1984, 1992; Crawley and Nachapong 1985; Crawley 1989; Mueller et al. 2005). For example, seeds produced on damaged mothers may be smaller and may develop into less vigorous seedlings than those produced in the absence of herbivory (e.g., Maun and Cavers 1971; Marquis 1984). In contrast, adaptive maternal effects of herbivory occur when maternal herbivory-induced changes in offspring trait expression, such as trichome production (Agrawal 2001; Holeski 2007), enhance the fitness of offspring growing under the same maternal herbivory conditions. To date, most studies examining the effect of herbiv-

\footnotetext{
${ }^{1}$ Author for correspondence; e-mail: janette.steets@okstate.edu.
}

Manuscript received December 2009; revised manuscript received January 2010. ory for plant fitness quantify effects on seed number and, to a lesser extent, progeny traits expressed early in development, such as seed mass and seedling size. In the only studies to explore the effects of maternal herbivory for offspring traits expressed later in development, Agrawal (2001, 2002) found that maternal herbivory to Raphanus raphanistrum affected components of progeny fitness, including seed mass, plant growth, flower production, and fruit mass; however, these maternal effects depended on family membership. Given the limited research that has been conducted to date on maternal effects of herbivory for offspring fitness, the potential cross-generational consequences of maternal foliar damage largely remain unknown.

Herbivory may result in mating system-dependent maternal effects if maternal herbivory differentially affects the quality of selfed and outcrossed progeny. The only study to examine mating system-dependent maternal effects of herbivory found that maternal herbivory reduced seedling biomass of selfed progeny more than it reduced that of potentially outcrossed progeny (Steets and Ashman 2004). However, herbivorymediated maternal effects on mating system may be even more complex because of interactions between progeny inbreeding level and resource allocation to progeny.

The expression of maternal effects may also depend on the growth environment offspring experience after dispersal (e.g., Stratton 1989; Wulff et al. 1994; Donohue and Schmitt 1998). For example, under competitive growth conditions, maternal effects in Erigeron annuus persist for a longer period in offspring ontogeny than they do under noncompetitive growth conditions (Stratton 1989). Furthermore, if environmental cues in the maternal generation are predictive 
of the progeny growth environment, then maternal effects may be adaptive (Donohue and Schmitt 1998; Sultan et al. 2009). With respect to herbivory, leaf area loss can be quite similar across years for numerous plant species (Filip et al. 1995). Thus, maternal herbivore damage may predict offspring herbivore condition, creating the opportunity for maternal effects of herbivory to be adaptive.

We examined maternal effects of herbivory in Impatiens capensis, which exhibits a mixed mating system by producing obligately selfing (cleistogamous [CL]) and facultatively outcrossing (chasmogamous $[\mathrm{CH}]$ ) flowers on an individual plant. Our previous work has shown that herbivory affects the mating system of I. capensis at two levels: (1) the proportion of reproduction that occurs through cleistogamy and (2) the CH outcrossing rate (Steets and Ashman 2004; Steets et al. 2006a). Overall, herbivory decreases whole-plant outcrossing, indicating that the effects of herbivory on proportional CL reproduction, which favors selfing, outweigh the effects of herbivory on the $\mathrm{CH}$ mating system, which favors outcrossing (Steets et al. 2006a). We have also found that maternal effects of artificial damage occur early in seedling development, with artificial defoliation of maternal plants causing a slight reduction in offspring cotyledon size and seedling biomass (Steets and Ashman 2004). However, whether maternal effects occur in response to natural herbivore damage and, if maternal effects occur, whether these effects persist throughout ontogeny or are influenced by offspring growth environment is unknown. Here we expand these earlier studies by asking the following questions: (1) Does natural herbivory to maternal plants affect offspring fitness-related traits in $I$. capensis? (2) Does herbivory to maternal plants differentially influence CL and CH offspring (i.e., are there mating systemdependent maternal effects of herbivory)? (3) Does the level of competition that offspring experience exacerbate or prolong the duration of maternal effects?

We hypothesized that maternal herbivory would differentially affect fitness-related traits of progeny derived from CL and from $\mathrm{CH}$ flowers (hereafter, $\mathrm{CL}$ and $\mathrm{CH}$ progeny). Mating system-dependent maternal effects may arise through at least two mechanisms. First, resource limitation due to leaf damage may lead to outcrossed seeds being provisioned with more resources than are selfed seeds (Stephenson 1981; Levri and Real 1998). For example, when $50 \%$ of leaf tissue of $I$. capensis maternal plants is artificially removed, the resulting CL offspring are significantly smaller in size than are $\mathrm{CH}$ progeny produced under the same maternal environmental conditions (Steets and Ashman 2004). In contrast, CL and $\mathrm{CH}$ offspring produced by undamaged maternal plants did not differ in seedling biomass (Steets and Ashman 2004). Second, mating system-dependent maternal effects of herbivory may manifest via differences in genetic quality of $\mathrm{CH}$ seeds produced under herbivory conditions. In wild I. capensis populations, herbivory causes an increase in the outcrossing rate of $\mathrm{CH}$ flowers (Steets et al. 2006a). Maternal plants that are subjected to greater herbivore pressure produce $\mathrm{CH}$ progeny that are more likely to be outcrossed, and thus these $\mathrm{CH}$ progeny may be more vigorous (e.g., larger in size, increased flower production) because of reduced inbreeding depression than those produced by maternal plants experiencing less herbivory. Thus, maternal effects might differ for $\mathrm{CH}$ and $\mathrm{CL}$ progeny as a result of mating system and resource changes in the former and allocation changes in the latter. Regardless of the underlying mechanism, given that $\mathrm{CH}$ and CL seeds differ in their demographic values and contributions to population growth (Steets et al. 2007), it is worth considering the net effect of maternal herbivory on progeny fitness.

\section{Material and Methods}

\section{Study System}

Impatiens capensis Meerb. (Balsaminaceae) is a native annual that occurs throughout moist forests in eastern North America (Schemske 1978). Among natural populations in Pennsylvania, Steets et al. (2006a) found broad variation in the outcrossing rate of $I$. capensis; a significant portion of this variation was due to herbivory. Herbivory is common in I. capensis populations, and vegetative damage in Pennsylvanian populations is primarily caused by chrysomelid beetles, leaf miners, caterpillars, aphids, grasshoppers, and katydids (Steets 2005).

\section{Experimental Design}

This experiment was part of a larger study aimed at understanding the consequences of herbivory for the mating system of $I$. capensis. Here we briefly summarize the methods of this experiment (for details, see Steets et al. 2006a). In one wild I. capensis population located near the Pymatuning Laboratory of Ecology in Crawford County, Pennsylvania (W population; Steets et al. 2006a), we randomly selected $141-\mathrm{m}^{2}$ plots. Plots within the population were separated from one another by at least $5 \mathrm{~m}$, and within each plot, seven focal maternal individuals were tagged. Plots were assigned to one of the following two treatments: (1) reduced or (2) ambient herbivory. Herbivory was reduced by applying two insecticides (Conserve [Dow AgroSciences, Indianapolis, IN] and Endeavor [Syngenta Crop Protection, Greensboro, NC]) biweekly to plants in the reduced-herbivory plots. These insecticides reduce herbivory by the primary herbivores observed in the population under study (J. A. Steets, personal observation). Conserve inhibits feeding by a variety of foliarfeeding insects, including lepidopterous larvae, chrysomelid beetles, thrips, leaf miners, and katydids. Endeavor targets sap-sucking aphids and whiteflies. These insecticides reduce herbivory without affecting pollinator visitation to or growth or reproduction of $I$. capensis (app. A in Steets 2005). Ambient herbivory plots were sprayed with water at the same frequency to serve as a control. Insecticide applications began prior to flowering and continued until $3 \mathrm{wk}$ prior to a frost that killed the majority of plants. On average, plants in the ambient treatment experienced 2.5 times more leaf damage than did individuals in the reduced-herbivory treatment (leaves damaged, $33 \% \pm 3.1 \%$ SE vs. $13 \% \pm 1.7 \%$ SE; Steets et al. 2006a); the two treatments are hereafter referred to as ambient and reduced maternal herbivory environments (MHEs), respectively. No differences in the type of damage were observed between ambient and reduced MHEs (J. A. Steets, personal observation). We haphazardly collected CL and $\mathrm{CH}$ seeds from maternal plants in both MHEs. Seeds were kept separate by seed type but were pooled across ma- 
ternal plants within a MHE; thus, the parentage of individual seeds in this experiment is unknown. Outcrossing rate differed among $\mathrm{CH}$ seeds from contrasting MHEs; on average, the outcrossing rate of $\mathrm{CH}$ seeds from the ambient and reduced MHEs was $0.56 \pm 0.24$ versus $0.33 \pm 0.09$, respectively (Steets et al. 2006a). Seeds were stored in distilled water in cell culture trays at $4^{\circ} \mathrm{C}$ for $\sim 4$ mo to break dormancy (Leck 1979). Once germinated, seeds were planted (treatments described below) in $10-\mathrm{cm}^{2}$ pots filled with Fafard \#4 soil (Conrad Fafard, Agawam, MA) and transferred to a greenhouse, where supplemental heating and lighting were provided.

We employed a randomized complete block design consisting of 40 blocks. Equal numbers of $\mathrm{CL}$ and $\mathrm{CH}$ seeds from each MHE were assigned to one of the following offspring competitive environments (hereafter, OCEs):

1. Competitors present: The focal plant was grown in the presence of intraspecific competitors. Competitors were seeds derived from $\mathrm{CH}$ flowers that were collected from the same population as the focal plants. For seeds assigned to this treatment, one focal seed and two competitor seeds were planted in a single pot. This density (300 plants $\left.\mathrm{m}^{-2}\right)$ is within the range of natural juvenile densities $\left(88-340\right.$ plants $\mathrm{m}^{-2}$; Steets et al. 2006b). Fifty-seven days after planting, the smaller of the two competitors was removed from the pot; this density (200 plants $\mathrm{m}^{-2}$ ) is within the range for adult I. capensis in the wild (4-300 plants $\mathrm{m}^{-2}$; Steets et al. 2006b).

2. Competitors absent: The focal plant was grown in the absence of competitors.

There were a total of 320 focal plants in the experiment $(2$ seed types $\times 2$ MHEs $\times 2$ OCEs $\times 40$ replicates). As all of the focal seeds did not germinate, the final number of plants in the experiment was 309. We watered the plants daily throughout the duration of the experiment.

For each focal individual, we recorded the date of emergence as the date cotyledons emerged and completely reflexed. At 60 $\mathrm{d}$ of growth, we harvested, dried (at $60^{\circ} \mathrm{C}$ for $2 \mathrm{~d}$ ), and weighed aboveground parts of focal plants from half of the blocks ( $N=156$ individuals across all treatments) to estimate aboveground dry biomass. Plants in the remaining 20 blocks ( $N=153$ individuals across all treatments) were followed through the reproductive phase (80 additional days of growth). At the end of the experiment, we quantified final plant height and total $\mathrm{CL}$ and $\mathrm{CH}$ flower production and estimated the mating system as the proportion of total flowers that were CL.

\section{Statistical Analyses}

We used mixed-model ANOVA or ANCOVA (PROC MIXED, SAS Institute, 1999) to test the fixed effect of MHE (ambient vs. reduced), OCE (competitors present vs. absent), offspring seed type (CL vs. $\mathrm{CH}$ ), and their interactions on date of emergence, early plant biomass, final plant height, total flower production, and proportional production of CL flowers. Block was included in all models as a random factor. For all traits except emergence date, date of emergence was included as a covariate because the duration of growth can affect size and reproductive traits. To meet normality assumptions of ANOVA, proportional production of CL flowers was arcsine-square-root transformed before analysis (Zar 1999). With respect to our hypotheses, a significant main effect of
MHE in the ANOVAs indicates that there are maternal effects of herbivory on offspring traits. A significant interaction between MHE and offspring seed type suggests that the expression of maternal effects depends on the seed type of the offspring. Finally, a significant interaction between MHE and OCE or among MHE, offspring seed type, and OCE indicates that expression of maternal effects or mating system-dependent maternal effects of herbivory depend on the competitive environment experienced by offspring. When we detected significant interaction terms, we investigated the interaction further by computing simple main effects (also known as interaction slices; Pedhazur 1982; Pedhazur and Pedhazur Schmelkin 1991) via the SLICE option in PROC MIXED (SAS Institute, 2007). Interaction slices assess the significance of a given factor (e.g., MHE) at specific levels of another factor (e.g., CL or $\mathrm{CH}$ seed type).

\section{Results}

\section{Effects of Maternal Herbivory Environment}

There was a significant main effect of MHE on emergence date, early plant biomass, final plant height, and total flower production (table 1; fig. 1). Across both seed types and both competition levels, progeny from the ambient MHE emerged $1.5 \mathrm{~d}$ later (ambient vs. reduced: $31.6 \pm 0.55 \mathrm{~d}$ vs. $30.1 \pm 0.53 \mathrm{~d}$ ) than did progeny from the reduced MHE. Despite their later timing of emergence, progeny produced in the ambient $\mathrm{MHE}$ were $23 \%$ larger in aboveground biomass $(0.64 \pm 0.030 \mathrm{~g}$ vs. $0.52 \pm 0.030 \mathrm{~g}$ ), were $16 \%$ taller as reproductive individuals $(69.5 \pm 1.59 \mathrm{~cm}$ vs. $60.0 \pm 1.54 \mathrm{~cm})$, and produced $16 \%$ more flowers $(62.3 \pm 2.31$ vs. $53.6 \pm 2.24)$ than progeny from the reduced MHE. Although not statistically significant, maternal plants subjected to ambient herbivory tended to produce offspring that reproduced relatively more through chasmogamy than through cleistogamy relative to offspring from reduced-herbivory mothers (table $1 ; P=0.08$; proportion CL: $0.68 \pm 0.0003$ vs. $0.72 \pm 0.0003)$.

\section{Dependence of Maternal Effects on Offspring Seed Type}

There was a significant interaction between maternal herbivory and progeny seed type for early plant biomass and total flower production (table 1; fig. $1 b, 1 d$ ), indicating that for these traits, the expression of maternal effects depended on progeny seed type. $\mathrm{CH}$ offspring produced by maternal plants experiencing ambient levels of herbivory weighed $28 \%$ more before reproduction and produced $32 \%$ more flowers than did CL offspring produced in the same MHE (table 2; fig. $1 b, 1 d$ ). CL and $\mathrm{CH}$ offspring produced in the reduced MHE did not differ in these traits (table 2; fig. $1 b$, 1d). In contrast, for timing of emergence, final plant height, and proportion of reproduction occurring through $\mathrm{CL}$ flowers, offspring seed type did not influence expression of maternal effects (table 1; fig. 1a, 1c, 1e).

\section{Influence of Offspring Competitive Environment on Expression of Maternal Effects}

The OCE affected the expression of maternal effects for emergence date, early plant biomass, plant height, and total 
Table 1

Summary of $\boldsymbol{F}$ Statistics and $\boldsymbol{P}$ Values for Mixed-Model ANCOVA on Date of Seedling Emergence, Early Plant Biomass, Final Plant Height, Total Flower Production, and Proportion of Cleistogamous (CL) Flower Production

\begin{tabular}{|c|c|c|c|c|c|c|c|c|c|c|}
\hline \multirow[b]{2}{*}{ Source } & \multicolumn{2}{|c|}{ Date of emergence } & \multicolumn{2}{|c|}{$\begin{array}{c}\text { Early plant } \\
\text { biomass }\end{array}$} & \multicolumn{2}{|c|}{ Final height } & \multicolumn{2}{|c|}{$\begin{array}{l}\text { Total flower } \\
\text { production }\end{array}$} & \multicolumn{2}{|c|}{$\begin{array}{l}\text { Proportion CL } \\
\text { flowers }\end{array}$} \\
\hline & $F$ & $P$ & $F$ & $P$ & $F$ & $P$ & $F$ & $P$ & $F$ & $P$ \\
\hline MHE & 4.0 & .05 & 8.5 & .004 & 19.1 & $<.0001$ & 8.8 & .004 & 3.0 & .08 \\
\hline OCE & 3.7 & .06 & 55.4 & $<.0001$ & 110.7 & $<.0001$ & 171.6 & $<.0001$ & 54.0 & $<.0001$ \\
\hline ST & .1 & .8 & 3.1 & .08 & 6.4 & .01 & 6.6 & .01 & 3.8 & .05 \\
\hline $\mathrm{MHE} \times \mathrm{ST}$ & .01 & .9 & 3.9 & .05 & .02 & .9 & 11.2 & .001 & .2 & .7 \\
\hline $\mathrm{MHE} \times \mathrm{OCE}$ & 50.8 & $<.0001$ & 11.1 & .001 & 15.2 & .0002 & 5.5 & .02 & 1.2 & .3 \\
\hline $\mathrm{ST} \times \mathrm{OCE}$ & .2 & .7 & 4.2 & .04 & .09 & .8 & .3 & .6 & 5.0 & .03 \\
\hline $\mathrm{MHE} \times \mathrm{ST} \times \mathrm{OCE}$ & - & - & - & - & - & - & 12.4 & .0006 & - & - \\
\hline
\end{tabular}

Note. $\quad \mathrm{MHE}=$ maternal herbivory environment; OCE $=$ offspring competitive environment; $\mathrm{ST}=$ seed type. Seedling emergence $\mathrm{df}=1,263$; early plant biomass $\mathrm{df}=1,129$; final plant height $\mathrm{df}=1,126$; total flower production $\mathrm{df}=1,125$; and proportion CL flower production $\mathrm{df}=1,126$. For all traits, block was included in the model as a random factor $(P>0.05$ for all traits). For early plant biomass, final plant height, total flower production, and proportion CL flower production, date of seedling emergence was included as a covariate $(P<0.0001$ for all traits). For models in which the three-way interaction was not significant $(P>0.1)$, the interaction term was dropped from the model (denoted by a dash).

flower production (significant MHE $\times$ OCE interaction term; table 1; fig. 2). However, the effect of competitive conditions varied among traits. For one trait (total flower production), not only were maternal effects of herbivory dependent on the competitive environment of the offspring, but they also varied with seed type (table 1; fig. 3).

Maternal effects of herbivory for timing of emergence show contrasting patterns with offspring competitive context (table 3). In the absence of competition, offspring from the reduced MHE emerged $6.5 \mathrm{~d}$ earlier than did offspring from the ambient MHE (fig. 2a). In contrast, when offspring were grown in the presence of competitors, those derived from the reduced MHE emerged $4 \mathrm{~d}$ later than did offspring from the ambient MHE (fig. 2a).

For early plant biomass and final plant height, maternal effects on these traits were evident only when the progeny developed under competitive conditions (table 3; fig. $2 b, 2 c$ ). Reducing maternal herbivory by $61 \%$ resulted in offspring that had $50 \%$ less aboveground biomass and were $30 \%$ shorter as reproductive adults than offspring produced in the ambient MHE when these offspring were grown in the presence of competitors (table 3; fig. $2 b, 2 c$ ).

For total flower production, the interactive effects of MHE and OCE depended on seed type (table 1; fig. 3). In the absence of competition, $\mathrm{CH}$ offspring from the ambient $\mathrm{MHE}$ produced $45 \%$ more flowers than did CL offspring produced in the same MHE, whereas $\mathrm{CH}$ offspring from the reduced MHE produced $13 \%$ fewer flowers than did CL offspring produced in this MHE (fig. 3, open symbols). In contrast, in the presence of competition, both CL and $\mathrm{CH}$ offspring from the ambient MHE produced more flowers than did offspring from the reduced MHE (fig. 3, filled symbols).

\section{Effects of Offspring Competitive Environment and Seed Type}

Similar to previous findings with I. capensis (Waller 1984; Schmitt and Ehrhardt 1987; Steets et al. 2006b, 2007), we found that both offspring growth environment and seed source affected offspring traits (table 1). Specifically, the presence of competitors reduced biomass before reproduction by $42 \%$ (competitors present vs. competitors absent: $0.42 \pm 0.030 \mathrm{~g}$ vs. $0.73 \pm 0.029 \mathrm{~g})$, reduced height by $30 \%(53.3 \pm 1.57 \mathrm{~cm}$ vs. $76.3 \pm 1.56 \mathrm{~cm})$, and reduced flower production by $50 \%$ $(38.8 \pm 2.29$ vs. $77.2 \pm 2.27)$, but it increased investment in CL flowers by $24 \%(0.77 \pm 0.0003$ vs. $0.62 \pm 0.0003)$. Plants derived from CL seeds were $8 \%$ shorter (CL vs. CH: $62.04 \pm 1.56 \mathrm{~cm}$ vs. $67.5 \pm 1.54 \mathrm{~cm}$ ), produced $12 \%$ fewer flowers $(54.3 \pm 2.28$ vs. $61.7 \pm 2.26)$, and invested more in selfing CL flowers $(0.72 \pm 0.0003$ vs. $0.68 \pm 0.0003)$ than did those derived from $\mathrm{CH}$ seeds. Interestingly, and not previously demonstrated, there was a significant interaction between OCE and offspring seed type for early plant biomass and proportional production of CL flowers (table 1). In the absence of competitors, $\mathrm{CL}$ and $\mathrm{CH}$ individuals do not differ in biomass (table 4; $\mathrm{CL}$ vs. $\mathrm{CH}: 0.74 \pm 0.042 \mathrm{~g}$ vs. $0.73 \pm 0.043 \mathrm{~g}$ ) or mating system (table 4 ; CL vs. $\mathrm{CH}$ : $0.62 \pm 0.001$ vs. $0.62 \pm 0.001)$. In the presence of competitors, $\mathrm{CH}$ individuals are $47 \%$ heavier than CL individuals (table 4 ; CL vs. $\mathrm{CH}: 0.34 \pm 0.043$ vs. $0.50 \pm 0.042 \mathrm{~g}$ ), and a greater proportion of their reproduction is through chasmogamy than cleistogamy (table 4; CL vs. $\mathrm{CH}: 0.82 \pm 0.001$ vs. $0.73 \pm 0.001)$.

\section{Discussion}

Our results demonstrate significant maternal effects of herbivory for offspring fitness-related traits. In general, although maternal herbivory reduces seed production in Impatiens capensis (Steets et al. 2006a), the results presented here show that it can also have positive effects for offspring traits. In addition, these maternal effects persisted well into offspring adulthood and affected reproductive traits. However, for many of the traits studied, the magnitude of maternal effect depended on offspring seed type and growth environment, suggesting that complex outcomes are possible for plant pop- 

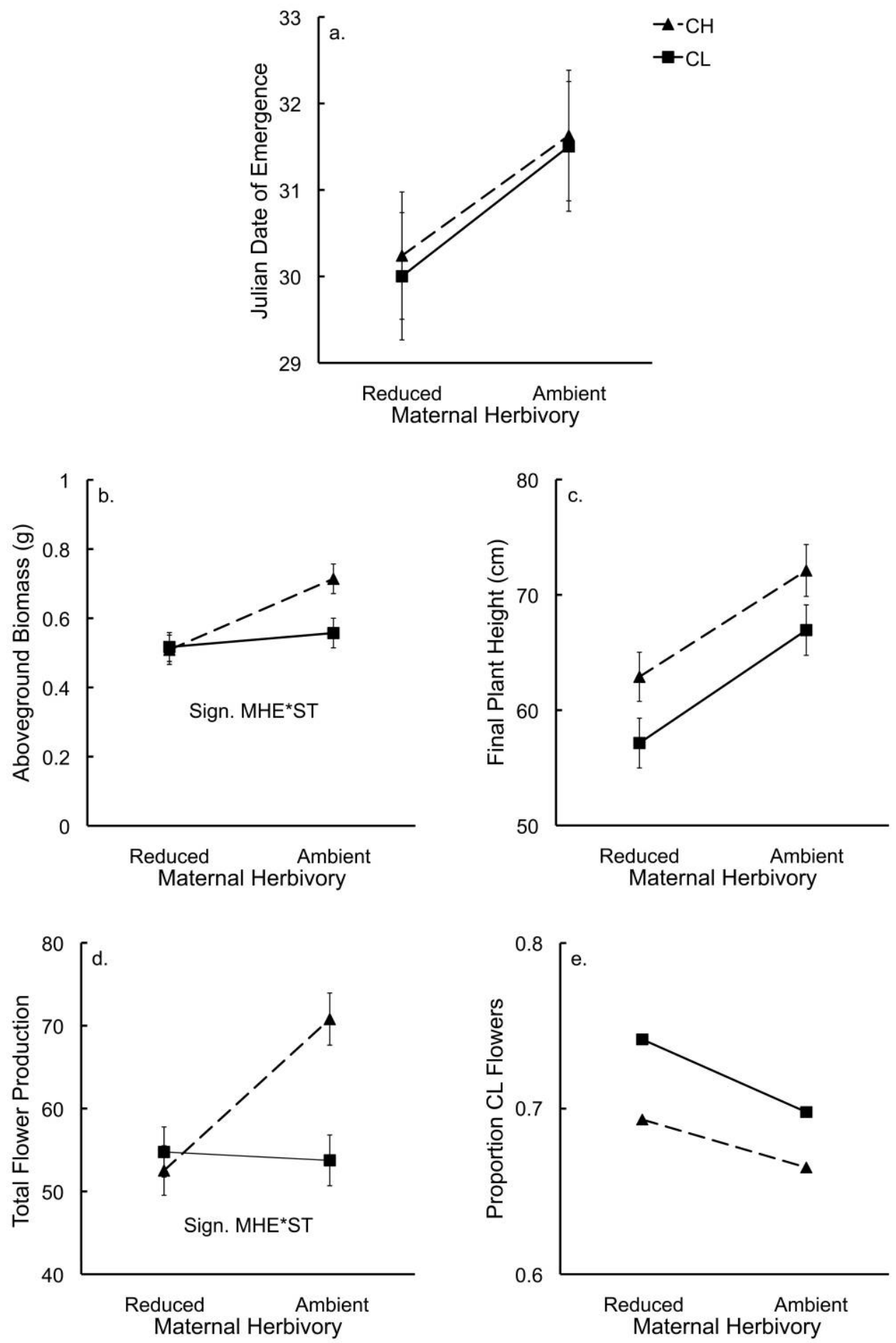

Fig. 1 Effect of maternal herbivory environment and offspring seed type for offspring traits. Least squares mean of $a$, Julian date of emergence, $b$, aboveground early plant biomass, $c$, final plant height, $d$, total flower production, and $e$, proportional production of cleistogamous $(C L)$ flowers for individuals derived from CL (squares) and chasmogamous ( $\mathrm{CH}$; triangles) seeds produced by maternal plants experiencing ambient or reduced levels of herbivory. Traits with a significant interaction between maternal herbivory and progeny seed type (Sign. MHE*ST) are indicated. Error bars represent $\pm 1 \mathrm{SE}$. 
Table 2

$F$ and $P$ Values of the Interaction Slices for the Effects of Maternal Herbivory and Progeny Seed Type on Early Plant Biomass and Total Flower Production of Impatiens capensis

\begin{tabular}{lccccc}
\hline & \multicolumn{2}{c}{ Early plant biomass } & & \multicolumn{2}{c}{ Total flower production } \\
\cline { 2 - 3 } Source & $F$ & $P$ & & $F$ \\
\hline Seed types, reduced herbivory & .02 & .9 & .3 & .6 \\
Seed types, ambient herbivory & 6.9 & .01 & 16.9 & $<.0001$ \\
Maternal herbivory, CH seed type & 11.9 & .0007 & 20.1 & $<.0001$ \\
Maternal herbivory, CL seed type & .5 & .5 & .06 & .8 \\
\hline
\end{tabular}

Note. Degrees of freedom (df) for early plant biomass and total flower production are listed in the note of table 1.

ulation dynamics. Below we expand on these findings and discuss the implications of our results for plant population dynamics.

\section{Maternal Effects of Herbivory}

Maternal herbivory can have strong positive or negative effects on seed mass and progeny growth traits (Wulff 1986; Agrawal 2001, 2002). In this study, maternal effects of herbivory were primarily positive. In $I$. capensis, we found that plants experiencing higher rates of herbivory produced progeny that were larger in size. Given research findings that demonstrate a trade-off between seed mass and number (Smith and Fretwell 1974; Westoby et al. 1992) as well as increases in seed mass with herbivory (Wulff 1986), our finding of increased offspring size with higher rates of maternal herbivory may be the result of altered patterns of resource allocation in maternal plants experiencing damage. Specifically, it is possible that maternal plants subjected to higher rates of herbivory allocate their limited resources into rearing fewer, larger seeds that develop into larger, more vigorous seedlings and adults, because herbivore damage significantly reduces $\mathrm{CH}$ and CL seed production (Steets et al. 2006a). In addition, when considering the plant size differences we found between offspring from ambient MHEs and those from reduced MHEs in light of the fact that plant size is positively correlated with seed mass in I. capensis (Waller 1985), it is likely that seeds produced in the ambient MHE were larger than those produced in the reduced MHE. Given that plant size is an important determinant of survival in I. capensis populations (Schmitt et al. 1987), maternal plants may be able to compensate for herbivory-mediated losses in seed production by producing fewer but more vigorous progeny that are able to outcompete those produced under more benign conditions. If the maternal effects of herbivory for progeny size are caused by differential resource allocation, then maternal effects on progeny traits expressed early in development may mediate maternal effects on final plant size and reproductive traits. For example, in Raphanus raphanistrum, plants derived from larger seeds produce more flowers (Stanton 1984).

Few researchers have investigated maternal effects of herbivory for reproductive traits of offspring. Agrawal (2001, 2002 ) found that maternal herbivory to $R$. raphanistrum affected components of progeny fitness, including seed mass, plant growth, flower production, and fruit mass; however, the strength and direction of maternal effects varied with family. Here we found significant positive maternal effects of herbivory for total flower production by offspring. Given that the maternal herbivore environment affects offspring traits related to life history (i.e., size, survival, reproduction), maternal effects of herbivory may have consequences for population dynamics, but this has yet to be quantified.

Competitive growth conditions have been shown to exacerbate expression of maternal effects in numerous species (e.g., Stratton 1989). Here we found that the OCE significantly affected the expression of maternal effects of herbivory for plant size and flower production (table 1; fig. 2). When $I$. capensis was grown in the presence of intraspecific competitors, offspring from the ambient MHE were significantly larger in size and produced more flowers than did those from the reduced MHE (table 1; fig. 2). In contrast, maternal effects of herbivory were not apparent among offspring grown in the absence of competitors (table 1; fig. 2). As $I$. capensis often grows in dense stands in which intraspecific competition is common (Schmitt et al. 1987; Steets et al. $2006 b$ ), and because the competitor-present treatment simulates intraspecific densities that are typical of those found in the wild (see "Material and Methods"), the results from this treatment are likely to be more relevant to natural populations than to those from the competitor-absent treatment. Our findings, as well as those of other researchers (e.g., Stratton 1989), highlight the importance of considering the offspring growth environment in the expression of maternal effects.

\section{Mechanisms of Mating System-Dependent Maternal Effects of Herbivory}

For progeny biomass and flower production, maternal effects of herbivory were evident only in $\mathrm{CH}$ offspring (fig. $2 b$, $2 d$ ). These mating system-dependent effects may be due to differential resource provisioning to $\mathrm{CL}$ and $\mathrm{CH}$ progeny (Steets and Ashman 2004) and/or herbivory-mediated alterations in maternal $\mathrm{CH}$ outcrossing rate (Steets et al. 2006a). First, it is possible that differential resource provisioning to $\mathrm{CL}$ and $\mathrm{CH}$ seeds, which develop at different positions on the plant and disperse different distances (Schmitt et al. 1985), underlies the response. For example, maternal effects are dependent on reproductive architecture in Polygonum bydropiper. Under optimal growth conditions, maternal plants produced terminal and axial offspring that did not differ in 

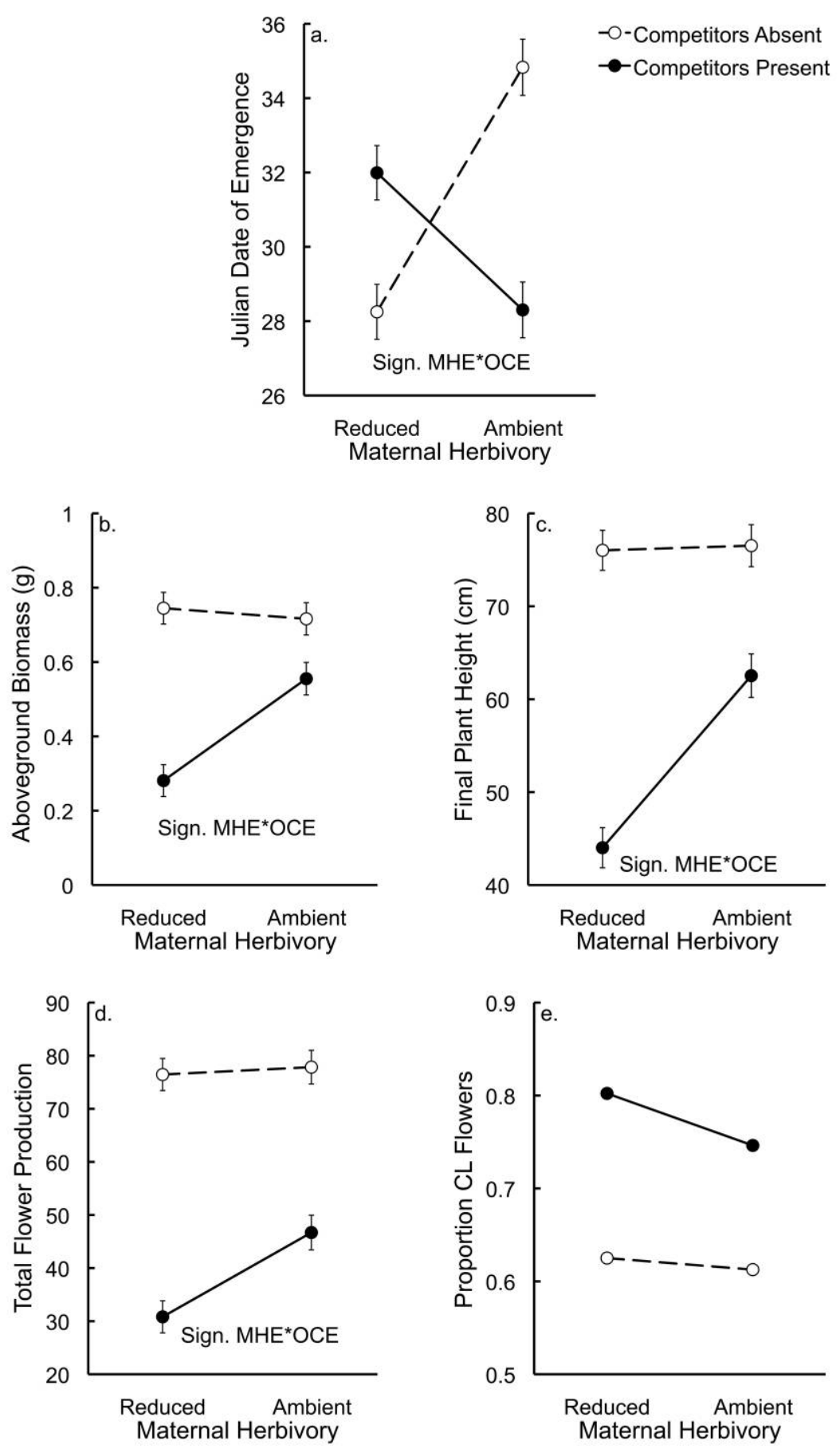

Fig. 2 Effect of maternal herbivory environment and offspring competitive environment for offspring traits. Least squares mean of $a$, Julian date of emergence, $b$, aboveground early plant biomass, $c$, final plant height, $d$, total flower production, and $e$, proportional production of cleistogamous $(C L)$ flowers for offspring that were produced by maternal plants experiencing ambient or reduced levels of herbivory and that were grown in the absence (open circles) or presence (filled circles) of competitors. Traits with a significant interaction between maternal herbivory environment and offspring competitive environment (Sign. MHE*OCE) are indicated. Error bars represent \pm 1 SE.

seedling size traits but, under stressful conditions, produced terminal offspring that developed faster and had more biomass than the axial individuals (Lundgren and Sultan 2005). Lundgren and Sultan (2005) attribute this maternal effect to differences in resource allocation to terminal and axial achenes; P. hydropiper prioritizes development of terminal offspring, which may disperse farther (given their position on the plant) than axial offspring. Similarly, in I. capensis, $\mathrm{CH}$ seeds disperse farther than CL seeds (Schmitt et al. 1985). Thus, maternal plants experiencing higher rates of herbivory 


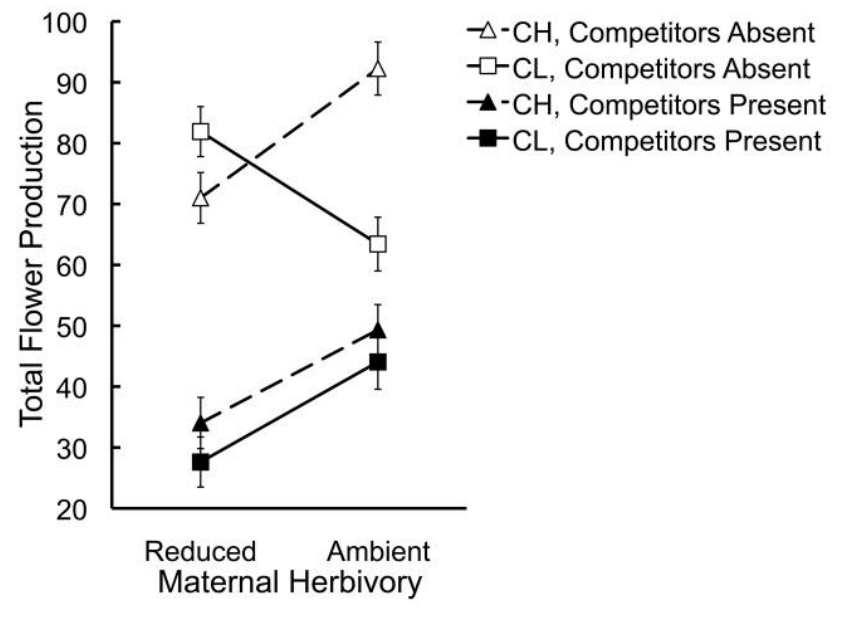

Fig. 3 Effect of maternal herbivory, seed type, and intraspecific competition for offspring total flower production. Open and filled circles represent competitor-absent and competitor-present treatments, respectively. Cleistogamous $(C L)$ individuals are denoted with squares and chasmogamous $(\mathrm{CH})$ individuals are denoted with triangles. Error bars represent $\pm 1 \mathrm{SE}$.

may prioritize the development of the far-dispersing $\mathrm{CH}$ seeds over that of the CL seeds, as the $\mathrm{CH}$ seeds may experience less competition and thus have higher rates of establishment and survival than the CL plants. However, it is also plausible that mating system-dependent maternal effects were due to differences in inbreeding level between $\mathrm{CH}$ progeny produced under ambient and reduced herbivory conditions. A $60 \%$ reduction in herbivory led to a $41 \%$ decrease in the outcrossing rate of $\mathrm{CH}$ flowers in $I$. capensis (Steets et al. 2006a). In addition, because inbreeding depression has been documented in I. capensis (Schmitt and Gamble 1990; Lu 2002), the mating system-dependent maternal effects we document for biomass and flower production may be due to the higher outcrossing and concomitant lower inbreeding depression of $\mathrm{CH}$ seeds produced under ambient herbivory conditions. Unfortunately, the experimental design employed in this study does not allow us to identify the specific mechanism underlying the mating system-dependent maternal effects, and future experiments will be needed to address this topic.

In a previous study, we found that maternal plants subjected to simulated herbivory produced CL offspring that were smaller in size than their $\mathrm{CH}$ equivalents and all progeny types from undamaged maternal plants (Steets and Ashman 2004). The difference in the direction of mating systemdependent maternal effects between previous work and this study may be due to differences in several aspects of experimental context. First, simulated herbivory may not elicit the same cross-generational responses as natural herbivory. For example, removal of leaf tissue with scissors does not induce resistance or transgenerational resistance in Raphanus raphanistrum, whereas within- and between-generation resistance occurs when caterpillar feeding damages maternal plants (Agrawal 2002). In addition, the maternal competitive environment differed between the two studies (i.e., Steets and Ashman 2004 and this study), and this may have contributed to differences in mating system-dependent maternal effects. In the simulated herbivory experiment (Steets and Ashman 2004), maternal plants were grown individually in pots and thus were not subjected to intraspecific competitive interactions that are common in I. capensis populations (Schmitt et al. 1987; Steets et al. 2006b). The natural competitive dynamics among maternal plants in this study may have resulted in more stressful growth conditions and, thus, differences in maternal effects on $\mathrm{CL}$ and $\mathrm{CH}$ seeds relative to the simulated herbivory experiment (Steets and Ashman 2004). Given the more realistic conditions of this study, our current findings likely better reflect cross-generational responses of I. capensis to herbivory in nature.

\section{Demographic Consequences of Maternal Effects}

Researchers are just beginning to examine the demographic consequences of parental environment (Beckerman et al. 2002; Galloway and Etterson 2007; Donohue 2009). By considering our findings of mating system-dependent maternal effects of herbivory for offspring biomass and total flower production in light of the difference in demographic value between I. capensis CL and CH individuals (Steets et al. 2007), we can predict the potential population dynamic consequences of these maternal effects. Here we found that $\mathrm{CH}$ offspring produced by maternal plants experiencing ambient herbivory were significantly larger and had greater flower production than CL individuals from the same MHE and individuals of both seed types produced in the reduced MHE (table 2; fig. $1 b, 1 d$ ). Because plant size is a significant predictor of survival in $I$. capensis populations (Schmitt et al. 1987), the greater size of $\mathrm{CH}$ individuals from ambient-

Table 3

$F$ and $P$ Values of the Interaction Slices for the Effects of Maternal Herbivory and Intraspecific Competition on Emergence Date, Early Plant Biomass, Final Plant Height, and Total Flower Production of Impatiens capensis

\begin{tabular}{|c|c|c|c|c|c|c|c|c|}
\hline \multirow[b]{2}{*}{ Source } & \multicolumn{2}{|c|}{ Date of emergence } & \multicolumn{2}{|c|}{$\begin{array}{l}\text { Early plant } \\
\text { biomass }\end{array}$} & \multicolumn{2}{|c|}{ Final plant height } & \multicolumn{2}{|c|}{$\begin{array}{l}\text { Total flower } \\
\text { production }\end{array}$} \\
\hline & $F$ & $P$ & $F$ & $P$ & $F$ & $P$ & $F$ & $P$ \\
\hline Competition, reduced herbivory & 13.8 & .0002 & 57.9 & $<.0001$ & 112.0 & $<.0001$ & 127.0 & $<.0001$ \\
\hline Competition, ambient herbivory & 40.1 & $<.0001$ & 6.6 & .01 & 17.7 & $<.0001$ & 48.4 & $<.0001$ \\
\hline Maternal herbivory, competitors absent & 42.1 & $<.0001$ & .2 & .6 & .02 & .9 & .1 & .7 \\
\hline Maternal herbivory, competitors present & 13.0 & .0004 & 20.1 & $<.0001$ & 35.6 & $<.0001$ & 14.6 & .0002 \\
\hline
\end{tabular}

Note. Degrees of freedom (df) for date of emergence, early plant biomass, final plant height, and total flower production are listed in table 1. 
Table 4

$F$ and $P$ Values of the Interaction Slices for the Effects of Intraspecific Competition and Progeny Seed Type on Early Plant Biomass and Proportional Production of Cleistogamous (CL) Flowers of Impatiens capensis

\begin{tabular}{lccccc}
\hline & \multicolumn{2}{c}{ Early plant biomass } & & \multicolumn{2}{c}{ Proportion CL flowers } \\
\cline { 2 - 3 } Source & $F$ & & & $F$ & $P$ \\
\hline Seed types, competitors absent & .04 & .8 & .04 & .8 \\
Seed types, competitors present & 7.2 & .008 & & 8.7 & .004 \\
Competition, CH seed type & 14.6 & .002 & & 13.3 & .0004 \\
Competition, CL seed type & 45.1 & $<.0001$ & & 46.5 & $<.0001$ \\
\hline
\end{tabular}

Note. $\quad$ Degrees of freedom (df) for early plant biomass and proportion CL flowers are listed in table 1.

herbivory maternal plants will likely translate into higher survival rates among these individuals. The potential increase in $\mathrm{CH}$ survival and fecundity of offspring produced under higher rates of herbivory relative to those produced in more benign herbivory conditions may have only moderately beneficial effects on I. capensis population growth because vital rates of $\mathrm{CH}$ individuals contribute disproportionately less to I. capensis population dynamics than do those of CL individuals (Steets et al. 2007). This interesting link between maternal effects of herbivory and population growth warrants further investigation.

\section{Conclusions}

Our study demonstrates that the maternal herbivory environment can have consequences for offspring fitness-related traits, including traits expressed later in life. Furthermore, the magnitude of maternal effects varied for selfed (CL) and largely outcrossed $(\mathrm{CH})$ offspring, and this difference was exacerbated by the offspring competitive environment. To better understand the ecological and evolutionary consequences of mating system-dependent maternal effects, demographic studies are needed that explicitly consider maternal effects on selfed and outcrossed individuals for population growth.

\section{Acknowledgments}

We thank Jeff Byrnes, Amy Ewing, Sarah Papperman, and Ellen York for assistance. The manuscript was improved by comments from three anonymous reviewers. This work was supported by the National Science Foundation (grants DEB0412120 and DEB-0449488) and Oklahoma State University. This is contribution 237 to the Pymatuning Laboratory of Ecology.

\section{Literature Cited}

Agrawal AA 2001 Transgenerational consequences of plant responses to herbivory: an adaptive maternal effect? Am Nat 157: 555-569.

2002 Herbivory and maternal effects: mechanisms and consequences of transgenerational induced plant resistance. Ecology $83: 3408-3415$.

Beckerman A, TG Benton, E Ranta, V Kaitala, P Lundberg 2002 Population dynamic consequences of delayed life-history effects. Trends Ecol Evol 17:263-269.

Crawley MJ 1983 Herbivory: the dynamics of plant-animal interactions. Blackwell Sciences, Cambridge.

1989 Insect herbivores and plant population dynamics. Annu Rev Entomol 34:531-564

Crawley MJ, M Nachapong 1985 The establishment of seedlings from primary and regrowth seeds of ragwort (Senecio jacobaea). I Ecol 73:255-261.

Donohue K 2009 Completing the cycle: maternal effects as the missing link in plant life histories. Philos Trans R Soc B 364:1059_ 1074.

Donohue K, J Schmitt 1998 Maternal environmental effects in plants. Pages 137-158 in TA Mousseau, CW Fox, eds. Maternal effects as adaptations. Oxford University Press, New York.

Filip V, R Dirzo, JM Maass, J Sarukhan 1995 Within- and amongyear variation in the levels of herbivory on the foliage of trees from a Mexican tropical deciduous forest. Biotropica 27:78-86.

Galloway LF 2001a The effect of maternal and paternal environments on seed characters in the herbaceous plant Campanula americana (Campanulaceae). Am I Bot 88:832-840.

$2001 b$ Parental environmental effects on life history in the herbaceous plant Campanula americana. Ecology 82:2781-2789.
Galloway LF, JR Etterson 2007 Transgenerational plasticity is adaptive in the wild. Science 318:1134-1136.

Holeski LM 2007 Within and between generation phenotypic plasticity in trichome density of Mimulus guttatus. I Evol Biol 20: 2092-2100.

Huxman TE, EP Hamerlynck, DN Jordan, KJ Salsman, SD Smith 1998 The effects of parental $\mathrm{CO}_{2}$ environment on seed quality and subsequent seedling performance in Bromus rubens. Oecologia 114: 202-208.

Lacey EP 1996 Parental effects in Plantago lanceolata L. I. A growth chamber experiment to examine pre- and post-zygotic temperature effects. Evolution 50:865-878.

Leck MA 1979 Germination behavior of Impatiens capensis Meerb. (Balsaminaceae). Bartonia 46:1-11.

Levri MA, LA Real 1998 The role of resources and pathogens in mediating the mating system of Kalmia latifolia. Ecology 79:16021609.

Lu Y 2002 Why is cleistogamy a selected reproductive strategy in Impatiens capensis (Balsaminaceae)? Biol L Linn Soc 75:543-553.

Lundgren MR, SE Sultan 2005 Seedling expression of crossgenerational plasticity depends on reproductive architecture. Am J Bot 92:377-381.

Marquis RJ 1984 Leaf herbivores decrease fitness of a tropical plant. Science 226:537-539.

1992 Selective impacts of herbivores. Pages 301-325 in RS Fritz, EL Simms, eds. Plant resistance to herbivores and pathogens: ecology, evolution, and genetics. University of Chicago Press, Chicago.

Maun MA, PB Cavers 1971 Seed production and dormancy in Rumex crispus. I. The effects of removal of cauline leaves at anthesis. Can I Bot 49:1123-1130. 
Mueller RC, BD Wade, CA Gehring, TG Whitham 2005 Chronic herbivory negatively impacts cone and seed production, seed quality and seedling growth of susceptible pinyon pines. Oecologia 143: 558-565.

Pedhazur EJ 1982 Multiple regression in behavioral research: explanation and prediction. 2nd ed. Holt, Rinehart \& Winston, New York.

Pedhazur EJ, L Pedhazur Schmelkin 1991 Measurement, design, and analysis: an integrated approach. Lawrence Erlbaum, Hillsdale, NJ.

Schemske DW 1978 Evolution of reproductive characteristics in Impatiens (Balsaminaceae): the significance of cleistogamy and chasmogamy. Ecology 59:596-613.

Schmitt J, J Eccleston, DW Ehrhardt 1987 Dominance and suppression, size-dependent growth, and self-thinning in a natural Impatiens capensis population. I Ecol 75:651-665.

Schmitt J, DW Ehrhardt 1987 A test of the sib-competition hypothesis for outcrossing advantage in Impatiens capensis. Evolution 41:579-590.

Schmitt J, DW Ehrhardt, D Swartz 1985 Differential dispersal of self-fertilized and outcrossed progeny in Impatiens capensis. Am Nat 126:570-575.

Schmitt J, SE Gamble 1990 The effect of distance from the parental site on offspring performance and inbreeding depression in Impatiens capensis: a test of the local adaptation hypothesis. Evolution 44:2022-2030.

Smith CC, SD Fretwell 1974 The optimal balance between size and number of offspring. Am Nat 108:409-506.

Stanton ML 1984 Seed variation in wild radish: effects of seed size on components of seedling and adult fitness. Ecology 65:1105-1112.

Steets JA 2005 Antagonists and mixed mating: consequences for the demography of Impatiens capensis (Balsaminaceae). PhD diss. University of Pittsburgh.

Steets JA, T-L Ashman 2004 Herbivory alters the expression of a mixed mating system. Am I Bot 91:1046-1051.
Steets JA, JL Hamrick, T-L Ashman 2006a Consequences of vegetative herbivory for maintenance of intermediate outcrossing in an annual plant. Ecology 87:2717-2727.

Steets JA, TM Knight, T-L Ashman 2007 The interactive effects of herbivory and mixed mating for the population dynamics of Impatiens capensis. Am Nat 170:113-127.

Steets JA, R Salla, T-L Ashman 2006b Herbivory and competition interact to affect reproductive traits and mating system expression in Impatiens capensis. Am Nat 167:591-600.

Stephenson AG 1981 Flower and fruit abortion: proximate causes and ultimate functions. Annu Rev Ecol Syst 12:253-279.

Stratton DA 1989 Competition prolongs expression of maternal effects in seedlings of Erigeron annuus (Asteraceae). Am I Bot 76: $1646-1653$

Sultan SE 1996 Phenotypic plasticity for offspring traits in Polygonum persicaria. Ecology 77:1791-1807.

Sultan SE, K Barton, AM Wilczek 2009 Contrasting patterns of transgenerational plasticity in ecological distinct congeners. Ecology 90:1831-1839.

Waller DM 1984 Differences in fitness between seedlings derived from cleistogamous and chasmogamous flowers in Impatiens capensis. Evolution 38:427-440.

1985 The genesis of size hierarchies in seedling populations of Impatiens capensis. New Phytol 100:243-260.

Westoby M, E Jurado, M Leishman 1992 Comparative ecology of seed size. Trends Ecol Evol 7:368-372.

Wulff RD 1986 Seed size variation in Desmodium paniculatum. I. Factors affecting seed size. LEcol 74:87-97.

Wulff RD, C Caceres, J Schmitt 1994 Seed and seedling responses to maternal and offspring environments in Plantago lanceolata. Funct Ecol 8:763-769.

Zar JH 1999 Biostatistical analysis. 4th ed. Prentice Hall, Upper Saddle River, NJ. 